\begin{tabular}{|c|c|c|}
\hline $\begin{array}{l}\text { PKS } \\
\text { PUBLIC } \\
\text { KNOWEDGE } \\
\text { PROJECT }\end{array}$ & $\begin{array}{c}\text { REVISTA DE GEOGRAFIA } \\
\text { (RECIFE) } \\
\text { http://www.revista.ufpe.br/revistageografia }\end{array}$ & $\begin{array}{l}\text { OJS } \\
\frac{\text { OPEN }}{\text { OPUNAL }} \\
\text { SYSTEMS }\end{array}$ \\
\hline
\end{tabular}

\title{
ESPACIALIZAÇÃO EM MAPAS DOS CASOS DE DENGUE, CHIKUNGUNYA E ZIKA VÍRUS NA CIDADE DE BARREIRAS-BA-BRASIL
}

\author{
Tarcísio Erundino Silva ${ }^{1}$, Robson Soares Brasileiro ${ }^{2}$
}

${ }^{1}$ Universidade Federal do Oeste da Bahia.E-mail:taerundino@hotmail.com

${ }^{2}$ Universidade Federal do Oeste da Bahia.E-mail:robson.brasileiro@ufob.edu.br

Artigo recebido em 23/07/2017 e aceito em 30/08/2018

\begin{abstract}
RESUMO
Este estudo espacializa em mapas as ocorrências de Dengue para os anos de 2015 e 2016 e Zica Vírus e Chikungunya para o ano de 2016, por não ter havido notificação dessas duas arboviroses no ano anterior, na cidade de Barreiras (BA). Também faz uma breve averiguação dos fatores, que podem estar contribuindo para a propagação do Aedes Aegypti nos bairros dessa cidade. As informações acerca dessas arboviroses para o período considerado são provenientes da Secretaria Municipal de Saúde - Vigilância Epidemiológica. Com os dados obtidos, foram confeccionados mapas separados em paletas de cores, tendo por finalidade indicar a quantidade de casos notificados. Com as análises de campo, foi perceptível uma relação direta entre a alta taxa de casos nos bairros considerados com o cuidado em relação ao saneamento básico e a infraestrutura, já que foi visto e registrado por meio de fotografias digitais parâmetros que demonstraram esses descuidos. Outrossim, foi ainda constatado que não há uma relação direta entre as condições socioeconômicas da população abrangida com os cuidados para que não haja a proliferação do Aedes Aegipytis, uma vez que a imprecaução das pessoas em relação à doença se propaga em praticamente toda a cidade.
\end{abstract}

Palavras-chave: Barreiras-Bahia; Dengue; Zica Vírus; Chicungunya.

\section{SPACIALIZATION IN MAPS OF THE CASES OF DENGUE, CHIKUNGUNYA AND ZIKA VÍRUS IN THE CITY OF BARREIRAS-BA-BRAZIL}

\begin{abstract}
This study aims to map the occurrences of Dengue for the year 2015 and the year 2016, and Zica Virus and Chikungunya for the year 2016, because there is no notification for those two arboviruses in the previous year, in the city of Barreiras-Bahia, in addition to making a brief investigation of the factors in the neighborhoods of that city that may be contributing to the spread of Aedes Aegypti. These cases portrayed in this city for this period were obtained from the Municipal Health Secretariat - Epidemiological Surveillance. Therefore, maps were made and were separated in color palettes in order to indicate the number of cases notified in the districts of that city. With the field analysis, a direct relationship between the high rate of cases in these neighborhoods and Lack of care with basic sanitation and infrastructure was perceived since parameters that demonstrated this were seen and recorded through digital photographs. It was also noted that there is no direct relationship between socioeconomic conditions and care with basic sanitation since this imprecation propagates in practically all the neighborhoods of that city.
\end{abstract}

Keywords: Barreiras-Bahia; Dengue; Zica Vírus; Chikungunya. 


\section{INTRODUÇÃO}

Com o desenvolvimento e propagação do meio-técnico-cientifico-informacional de modo massificado, o ser humano vem obtendo êxito na superação de diversos desafios, dentre os quais, o rompimento da barreira tempo e espaço, onde a transferência de informações a lugares que estão a grandes distâncias entre si acontecem praticamente a tempo real no ciberespaço a partir do desenvolvimento de ferramentas que possibilitam uma maior eficiência e rapidez na confecção de produtos mercantis e o acesso ao conhecimento de forma mais flexível e sem burocracias. No entanto, nesse cenário de evolução técnico-científica, ainda se têm de enfrentar vários desafios, dentre outros destaca-se aquele foco deste artigo que é espacializar mediante emprego do processamento digital de imagens e carta digitais em SIG, para analisar os focos do minúsculo mosquito Aedes Aegipyti, que tem sido um grande problema e desafio para sociedade contemporânea, considerando que esse mosquito é responsável pela proliferação de doenças como a Dengue, o Zica Vírus e o Chikungunya, causadoras de óbitos e sequelas na população mundial.

Apesar dos esforços crescentes e incentivo de práticas que possam contribuir com a erradicação do mosquito, nota-se que sua proliferação ainda tem sido de forma exponencial, demonstrando a necessidade de mudança nas estratégias ao seu combate.

Nesse sentido, o uso do conhecimento transdisciplinar é de extrema importância na superação desse desafio, uma vez que, quanto mais ferramentas e mecanismos houverem disponíveis no trato dessas questões, maiores serão as chances de minimizar e quiçá dizimar o Aedes Aegipyti. Ademais, ideias inovadoras podem implementar e/ou facilitar novas pesquisas e este estudo tem como finalidade contribuir de alguma forma para a ampliação de estratégias de combater e erradicar o Aedes Aegipyti.

Esta pesquisa teve como recorte espacial os bairros Jardins, Cidade Nova, Copacabana, Parque Verde, Barreiras II, Buritis, Alphaville, Jardim Vitória, Mimoso, Sombra da Tarde, Flamengo, Serra do Mimo, Bandeirantes, Aratu, Ribeirão, Antônio Geraldo, Recanto dos Pássaros, JK, Bela Vista, Rio Grande, Novo Horizonte, Renato Gonçalves, Vila Regina, Boa Sorte, Morada Nobre, Vila de Sás, Santo Antônio, São Sebastião, Cascalheiras, Morada da Lua, Loteamento São Paulo, São Miguel, Vila Nova, Vila dos Funcionários, São Pedro, Arboreto, Barreiras I, Vila Amorim, Centro, Vila Brasil, Sandra Regina, Ouro Branco, Barreirinhas, Santa Luzia, Vila Rica, da cidade de Barreiras-BA. A referida cidade está inserida na Bacia Hidrográfica do Rio Grande, localizada no Oeste do estado da Bahia (mapa $01)$. 
Em relação aos aspectos ambientais do recorte espacial investigado, Guadagnin et al. (2011) retrata que o município de Barreiras apresenta graves problemas, atribuindo isso à constante expansão agrícola e urbana que não possui concomitância com um correto planejamento, o que resulta no descuido com a vegetação do tipo mata ciliar. Ainda segundo esses autores isso tem comprometido a quantidade e qualidade da água dos rios de maior porte.

Mapa 01- Localização da cidade de Barreiras (BA).

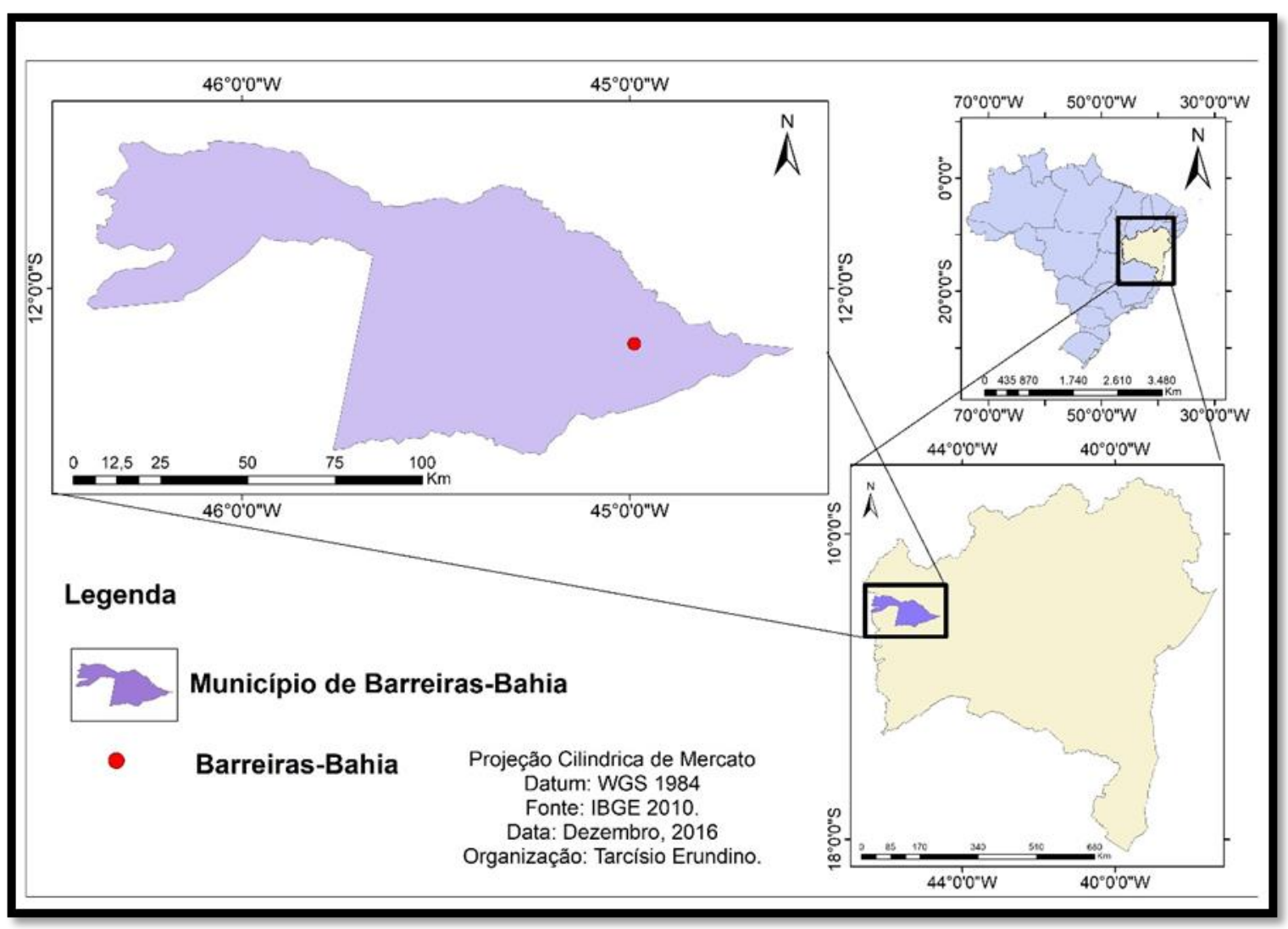

Conforme MOREIRA e SILVA (2010, p. 14), "Na região central da bacia verificamse áreas de tensão ecológica, as quais são caracterizadas pela transição das vegetações de cerrado, caatinga e florestas estacionais". Estes autores ainda retratam que, "O regime pluviométrico na bacia é caracterizado por dois períodos bem distintos: o chuvoso, que se estende de outubro a abril, com maiores índices no mês de dezembro; e o seco, que se estende de maio a setembro, com estiagem mais crítica de julho a setembro" (Idem, p. 12).

A cidade de Barreiras atualmente conta com uma população de aproximadamente 155.519 mil habitantes (IBGE, 2016). Apresenta um Produto Interno Bruto per capita (PIB 
per capita) de 19.045,98 reais, segundo dados divulgado pelo Instituto Brasileiro de Geografia e Estatística (IBGE) no senso de 2010, revisado em 2013.

O total da população e os números do PIB per capita demonstram que a cidade de Barreiras vem se expandindo de forma considerável, com base na sua vocação agrícola, do agronegócio, consolidado na região, o que por sua vez projeta esta cidade no cenário regional, nacional e mesmo internacional. Entretanto, esse crescimento na dinâmica econômica dessa cidade vinculado ao agronegócio não trouxe consigo infraestrutura urbana, mas sim um legado de precarização social a muitos bairros da cidade, principalmente aqueles mais periféricos e de classes sociais menos favorecidas.

Nesse sentido, o crescimento econômico desarticulado do desenvolvimento sócio ambiental, ocasionou pouco ou quase nenhuma implementação de serviços de saneamento básico e infraestrutura essenciais a sua população. Como resultado disto, veio o surgimento de vetores de doenças como as apresentadas neste trabalho.

A abordagem da Geografia da Saúde a partir das técnicas do geoprocessamento permite ao pesquisador realizar análises mais detidas e refinadas dos fatores e vetores de epidemias que assolam determinados espaços, principalmente em grandes e medias cidades. Além disso, as técnicas do geoprocessamento aplicadas à saúde, a partir de uma abordagem holística, pode proporcionar o planejamento e a definição de políticas públicas mais eficazes e precisas, para determinados territórios carentes em ações na área da saúde pública.

Para o entendimento da relação entre espaço e saúde, é fundamental o conhecimento dos sucessivos sistemas técnicos (GUIMARÃES, 2015, p. 58), e, nesse contexto, o geoprocessamento enquanto um conjunto de tecnologias de coleta e tratamento de dados e manipulação associadas a análises interpretativas do espaço geográfico pode proporcionar o desenvolvimento de ações mais pontuais na área de saúde, a partir da manipulação de dados espaciais.

Segundo Barcelos et al. (2008, p. 60) "para que os dados gerados pelos sistemas de informações em saúde sejam mapeados, os eventos de saúde devem ser relacionados a um conjunto de objetos geográficos ou unidades espaciais previamente construídas, como bairros, setores censitários, lotes ou trechos de logradouros".

Neste trabalho, o emprego do SIG permitiu espacializar em mapas as ocorrências das três arboviroses realcionadas ao Aedes Aegypti, que no Brasil é o mosquito associado, até o momento, à transmissão da: Dengue, Chikungunya e Zika Vírus. 
Segundo os dados obtidos na Secretaria de Vigilância em Saúde - Ministério da Saúde, houve, para o ano de 2015, conforme o Boletim Epidemiológico (BE), volume 46, referente à semana epidemiológica (SE) 48, que ocorreu de 04/01/15 a 05/12/15, 1.587.080 notificações prováveis de dengue no Brasil. Ainda segundo este BE, a região Nordeste foi a que apresentou o segundo maior número de ocorrências no país, com 293.567 casos prováveis. A maior incidência desses casos foi retratada na região Sudeste (997.268) e a menor na região Norte (31.689). Na região Nordeste o estado da Bahia apresentou o terceiro maior número de notificações com 51.095 casos prováveis, tendo a maior incidência ocorrida em Pernambuco, com 92.395 casos prováveis e depois o Ceará, com 63.215 casos.

Para os casos de febre de Chikungunya, nesse mesmo ano, houve 38.332 notificações prováveis no país. Deste total, foram confirmados seis óbitos distribuídos entre os estados da Bahia, Sergipe, São Paulo e Pernambuco. Quanto a febre transmitida pelo vírus Zika, só houve confirmação da transmissão autóctone no país a partir de abril de 2015, com a determinação em laboratório de três óbitos em São Luís/MA, Benevides/PA e Serrinha/RN.

Para o ano de 2016, de acordo com o Boletim Epidemiológico (BE), volume 47, da Semana Epidemiológica (SE), de 3/1/2016 a 17/09/2016, houve o registro de 1.438.624 notificações prováveis de dengue no país. A região Nordeste manteve-se ainda para esse ano na terceira posição em números de incidência, apresentando um aumento em relação ao ano anterior de 317.483 casos. Entretanto, a maior quantidade de notificações continuou sendo atribuída à região Sudeste com 842.741 casos, sendo este contingente um pouco menor do que foi apresentado no ano de 2015. A região Norte continuou apresentando a menor incidência com 37.854 notificações, porém, com um contingente maior em relação ao ano de 2015.

Para o ano de 2016, o estado da Bahia passou da terceira posição do ano anterior, para a segunda posição com 62.640 casos. A primeira posição ainda foi de Pernambuco, que apresentou um contingente menor em relação ao ano anterior de 66.069 casos. O estado do Ceará passou da segunda para a quarta posição com 49.672 casos, enquanto a terceira posição foi para o Rio Grande do Norte com 57.214 casos.

Ainda segundo o Boletim Epidemiológico (BE), no ano de 2016, houve 236.287 notificações para os casos de febre de Chikungunya, com maior incidência na região Nordeste. Para os casos de febre do vírus Zika, foram registradas 200.465 notificações prováveis, com maior incidência na região Centro-Oeste.

Tendo em vista a problemática que essas arboviroses vem trazendo em âmbito mundial, essa pesquisa procura fomentar o entendimento da dispersão dessas doenças na 
cidade de Barreiras (BA), iniciando com a espacialização em mapas das notificações para os casos de Dengue, Chikungunya e Zika Vírus para os anos de 2015 e 2016. Desse modo, espera-se contribuir, com esses mapas indicadores de risco urbano de transmissão dessas arboviroses nos bairros investigados, para que seja possível a realização de uma estratégia de controle.

\section{PROCEDIMENTOS METODOLÓGICOS}

A pesquisa foi preliminarmente fundamentada na realização de consultas bibliográficas para um maior aprofundamento do tema pesquisado. Posteriormente, foram solicitados na Secretaria Municipal de Saúde - Vigilância Epidemiológica de Barreiras os dados contendo as notificações dos casos de Dengue, Zica Vírus e Chikungunya dos anos de 2015 e de 2016, objetivando com isso a confecção de mapas. Porém, para o ano 2015 a secretaria só dispõe dos dados relacionados aos casos de dengue.

O georreferenciamento compreende a transformação geométrica que relaciona coordenadas de imagem (linha, coluna) com coordenadas de um sistema de referência (PIROLI, 2010). Nesta pesquisa foi empregado o software ArcGis 9.3 da ESRI de uso do laboratório de geoprocessamento da Universidade Federal do Oeste da Bahia. Os arquivos vetoriais em shapefiles dos bairros pesquisados, foram cedidos pela Secretária Municipal de Planejamento e Desenvolvimento Econômico da cidade de Barreiras.

Como resultado foram montados dois mapas com os casos de Dengue, um referente ao ano de 2015 e outro ao de 2016. Como os casos de Zica e Chikungunya só foram retratados na cidade a partir de 2016, então elaborou-se um mapa para cada uma dessas arboviroses nesse ano.

Nos mapas citados acima, de um modo geral, foram utilizadas três paletas de cores diferentes, que teve como objetivo indicar o quão intenso foram as notificações dessas arboviroses nos bairros da cidade de Barreiras.

Sendo que, as cores brancas indicam a ausência de notificação, as paletas de cores que partem de um verde mais suave até um verde mais intenso indicam de uma até quarenta notificação por bairro, sendo separadas quatro paletas de tonalidades diferentes de verde, representando os casos em que houve uma a dez notificações, onze a vinte, vinte e uma a trinta e de trinta e uma a quarenta.

Nos bairros que houveram de quarenta e uma até cem notificações, foram representados por cores que partem de um laranja claro até o vermelho. Diferenciadas em três 
paletas distintas, a que possui coloração laranja claro foi usada para representar os casos que tiveram de quarenta e uma a cinquenta notificações, o laranja escuro representa os casos com cinquenta e uma a sessenta notificações e o vermelho foi usado para apontar as áreas de maiores riscos, com notificações entre noventa a cem.

\section{RESULTADOS E DISCUSSÕES}

O quadro abaixo apresenta informações que possibilitam realizar uma análise comparativa entre o número de notificações de casos de Dengue acima de vinte (20) ocorrências por bairros na cidade de Barreiras-BA. Para esta análise comparativa tomou-se com referência os dados fornecidos pela Secretaria Municipal de Saúde e Vigilância Epidemiológica da referida cidade para os anos de 2015 e 2016. A opção por trabalhar com notificações acima de vinte ocorrência está relacionada a expressividade das ocorrências, pois em outros bairros apenas constatou-se ocorrências isoladas, isto é, um quantitativo numericamente inexpressível de casos.

Ao analisar o quadro abaixo verifica-se que em alguns bairros o número de ocorrências de dengue acima de 20 casos para o ano de 2016 teve uma redução bastante expressiva em relação ao número de ocorrências registradas no ano de 2015 pela Secretaria Municipal de Saúde e Vigilância Epidemiológica de Barreiras-BA. Essa constatação é vista como algo positivo. Essa diminuição no número de ocorrências de casos de dengue em alguns dos bairros selecionados no quadro abaixo pode ser devido a uma melhor atuação dos órgãos municipais competentes pelo monitoramento dessas áreas.

Entretanto, na referida análise comparativa observa-se também que em alguns bairros o quantitativo de casos de dengue diagnosticados no ano de 2016 ainda continuam muito próximo daqueles constatados no ano de 2015 pela Secretaria de Saúde e Vigilância Epidemiológica de Barreiras-BA.

QUADRO 01 - Quadro comparativo entre notificações de casos de Dengue entre 2015 e 2016 em bairros selecionadosde Barreiras (BA).

\begin{tabular}{|l|c|c|l|c|c|}
\hline Bairros & $\mathbf{N}^{\mathbf{0}}$ Casos & Ano & Bairros & $\mathbf{N}^{\mathbf{0}}$ Casos & Ano \\
\hline Arboreto & 22 & 2015 & Arboreto & 09 & 2016 \\
\hline Barreirinhas & 57 & 2015 & Barreirinhas & 36 & 2016 \\
\hline Centro Habitacional & 47 & 2015 & Centro & 27 & 2016 \\
\hline $\begin{array}{l}\text { Conjunto } \\
\text { Barreirinhas I }\end{array}$ & 2015 & $\begin{array}{l}\text { Conjunto Habitacional } \\
\text { Barreirinhas I }\end{array}$ & 22 & 2016 \\
\hline Jardim Ouro Branco & 51 & 2015 & Jardim Ouro Branco & 26 & 2016 \\
\hline Morada da Lua & 28 & 2015 & Morada da Lua & 40 & 2016 \\
\hline Santa Luzia & 96 & 2015 & Santa Luzia & 99 & 2016 \\
\hline Sandra Regina & 41 & 2015 & Sandra Regina & 20 & 2016 \\
\hline São Miguel & 22 & 2015 & São Miguel & 11 & 2016 \\
\hline
\end{tabular}




\begin{tabular}{|l|c|c|l|c|c|}
\hline São Paulo & 21 & 2015 & São Paulo & 21 & 2016 \\
\hline São Pedro & 30 & 2015 & São Pedro & 19 & 2016 \\
\hline Vila Amorim & 33 & 2015 & Vila Amorim & 26 & 2016 \\
\hline Vila Brasil & 43 & 2015 & Vila Brasil & 20 & 2016 \\
\hline Vila dos Funcionários & 21 & 2015 & Vila dos Funcionários & 09 & 2016 \\
\hline Vila Nova & 23 & 2015 & Vila Nova & 27 & 2016 \\
\hline Vila Rica & 100 & 2015 & Vila Rica & 82 & 2016 \\
\hline
\end{tabular}

Fonte: Secretaria Municipal da Saúde e Vigilância Epidemiológica de Barreiras-BA, 2015 e 2016.

Tendo como referência os dados apresentados no quadro acima, vale destacar que na região geralmente os meses de outubro, novembro, dezembro são chuvosos, há não ser que haja algumas atipicidades, sendo assim, esses aspectos podem agravar os índices de casos de Dengue na cidade.

\section{Espacialização Em Mapas}

A confecção dos mapas permitiu espacializar as notificações que houveram para os casos de dengue, no ano de 2015, e de Dengue, Chikungunya e Zika vírus, no ano de 2016.

No ano de 2015 (mapa 02), houve somente notificação para os casos de dengue, que foram georreferenciados em quarenta e seis bairros da referida cidade.

É possível notar que os casos de dengue, assim como demonstrado no mapa 02, para o ano de 2015 tiveram de noventa a cem notificações somente em dois bairros da cidade de Barreiras, sendo eles o Santa Luzia e o Vila Rica, possivelmente algo que pode justificar esse fato são as vulnerabilidades de saneamento básico e infraestruturais nesses bairros, como averiguada por meio das campanhas de campo realizadas.

Esses bairros encontram-se nas áreas periféricas da cidade e neles foram notados a presença de muitos terrenos baldios, sem os devidos cuidados, além de grandes quantidades de lixos espalhados, muitos dos quais com potencial para acumulação de água e concomitante possível proliferação do Aedes Aegypti, a exemplo tem-se pneus e garrafas pet (fotografias: 01 e 02).

Entretanto, percebe-se no mapa 02 cinco bairros possuindo entre quarenta e uma e sessenta notificações, todavia soma-se a esses bairros o Centro da cidade e os bairros Barreirinha, Ouro Branco e Sandra Regina, locais onde as condições de saneamento e infraestrutura são melhores, no entanto, também estão mais próximos ao rio que corta a cidade de Barreiras (Rio Grande) e que por vezes facilita o empoçamento de água que se tornam locais propícios para a proliferação do Aedes Aegypti. Tem-se inclusos nessa faixa de 
notificação o bairro Vila Brasil, que além de estar nas proximidades do rio Grande, possuem precária condições estruturais.

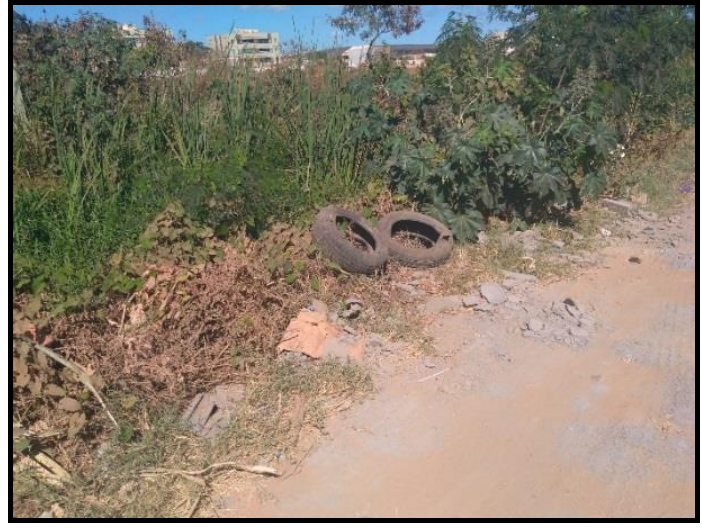

Fotografia 01: Rua no Bairro Vila Rica Barreiras. Autor: Tarcísio Erundino Silva, 2017.

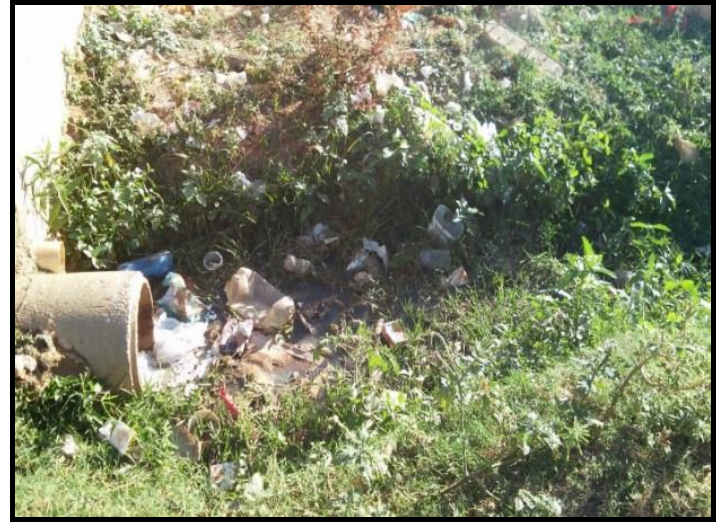

Fotografia 02: Rua no Bairro Santa Luzia Barreiras. Autor: Tarcísio Erundino Silva, 2017.

É possível observar também no mapa 02 os bairros que possuem notificações que variam de uma a quarenta, de um modo geral, os bairros que estão enquadrados nessa faixa possuem maiores notificações quando estão alocados nas áreas mais suburbanas e com precárias condições de gerenciamento de resíduos e infraestrutura.

Mapa 02 - Representação dos casos de dengue nos bairros da cidade de Barreiras-BA no ano de 2015.

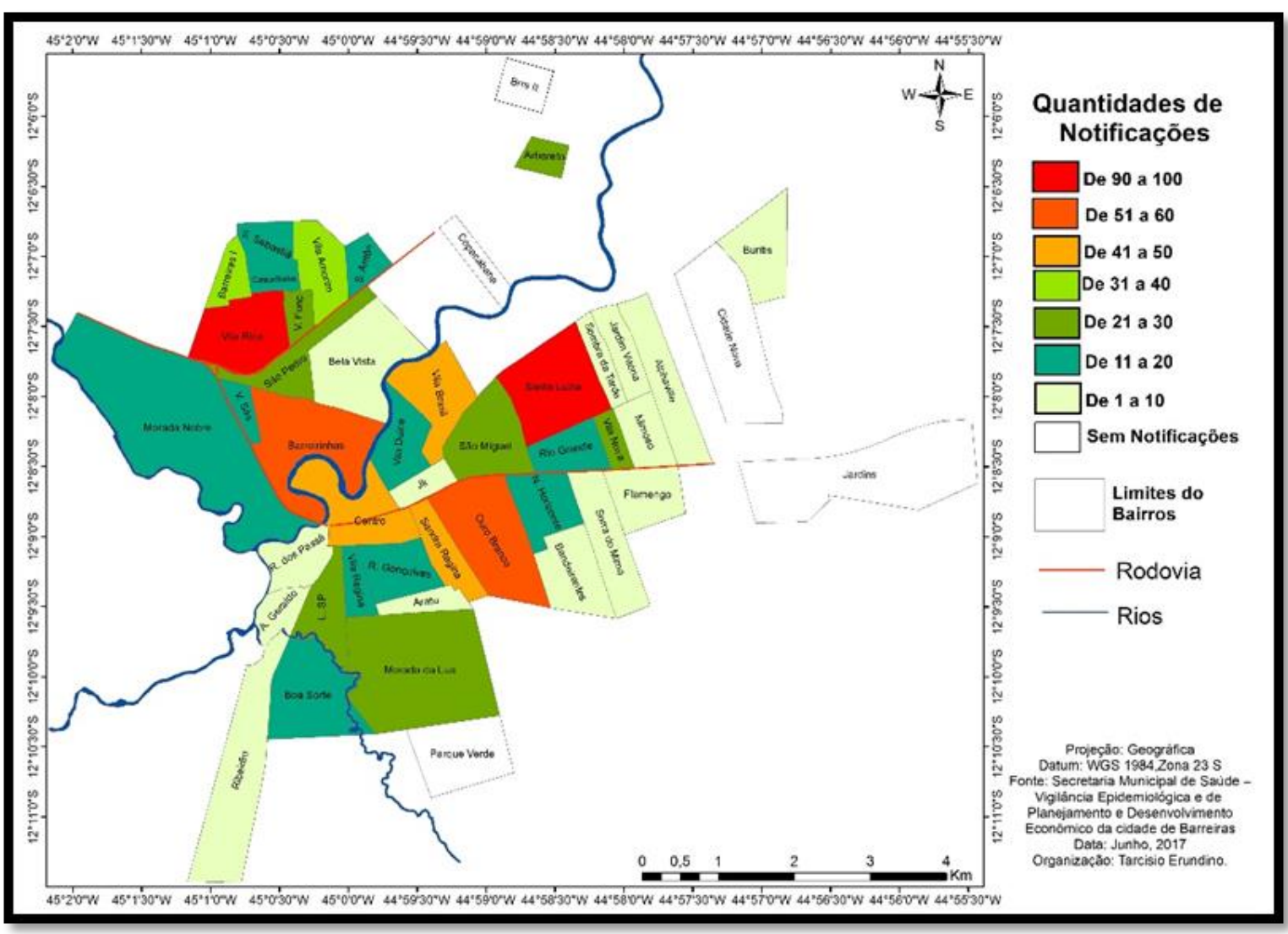


Com a confecção do mapa 03 em que está representando as ocorrências de dengue nos bairros da cidade de Barreiras para o ano de 2016, é possível notar, em comparação com o mapa elaborado para essa arbovirose do ano de 2015 (mapa 02), que houve uma significativa redução nas notificações. Uma vez que, as faixas entre quareta e uma a sessenta notificações retratadas anteriormente no mapa 02 já não aparecem no mapa 03 e os bairros que se enquadram na faixa entre uma a dez notificações passaram de quatorze a vinte e sete bairro. No entanto, os bairros Vila Rica e Santa Luzia, continuaram enquadrados em área de alto índice de notificação.

Mapa 03 -Representação dos casos de dengue nos bairros da cidade de Barreiras-BA no ano de 2016.

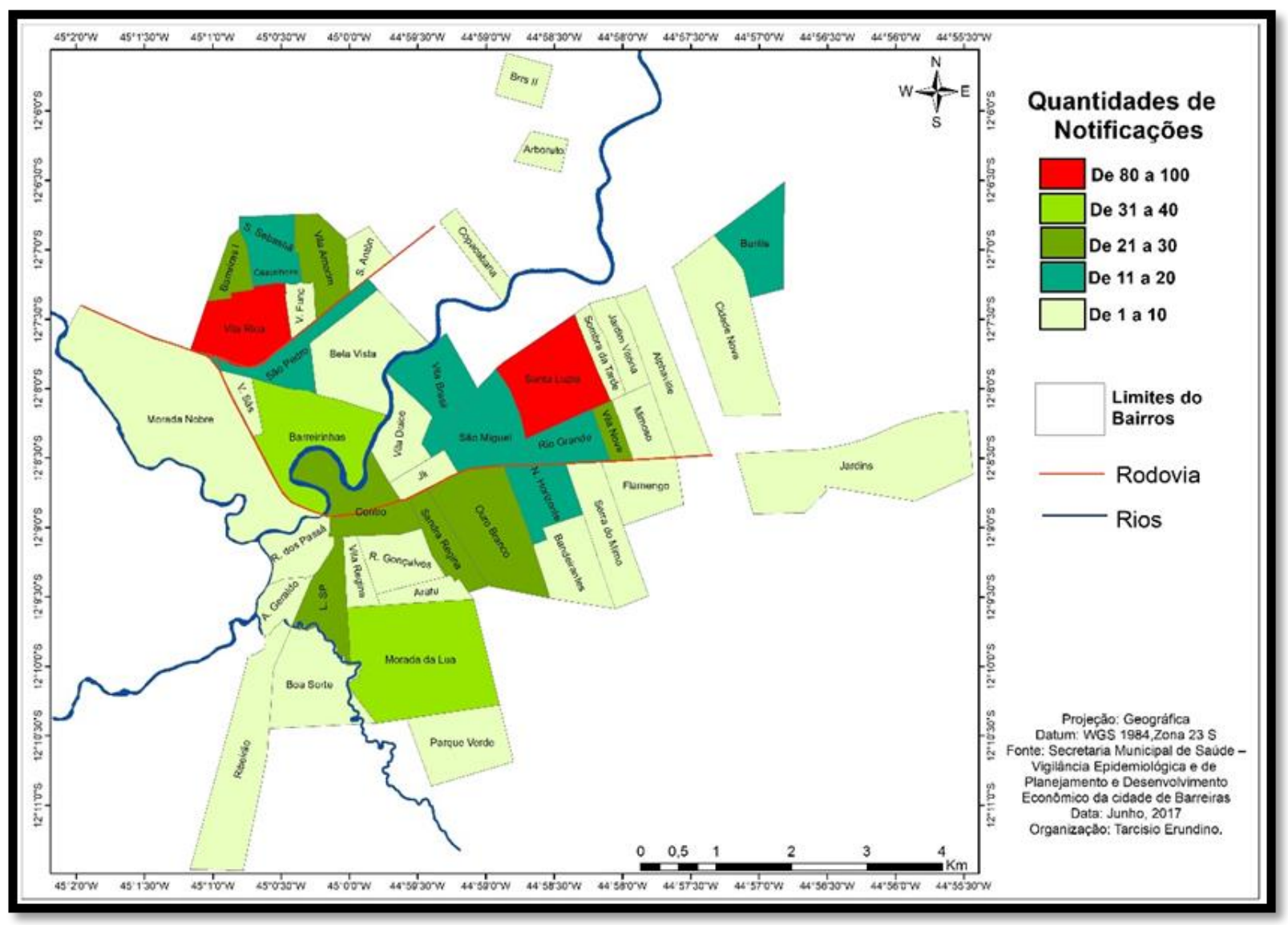

Os casos de Chikungunya e Zica Vírus só passaram a ter notificação na cidade de Barreiras a partir de 2016. Sendo que a Chikungunya foi notificada somente em uma faixa de uma a dez em 21 bairros dessa cidade e o Zica Vírus na faixa de uma a dez e de onze a vinte e uma, onde os bairros Vila Rica e Santa Luzia, que estão enquadrados na faixa de onze a vinte e uma notificações, permaneceram como áreas com as maiores notificações, como observado nos mapas 02 e 03 . 
Mapa 04 - Representação dos casos de Chikungunya nos bairros da cidade de Barreiras-BA referente ao ano de 2016

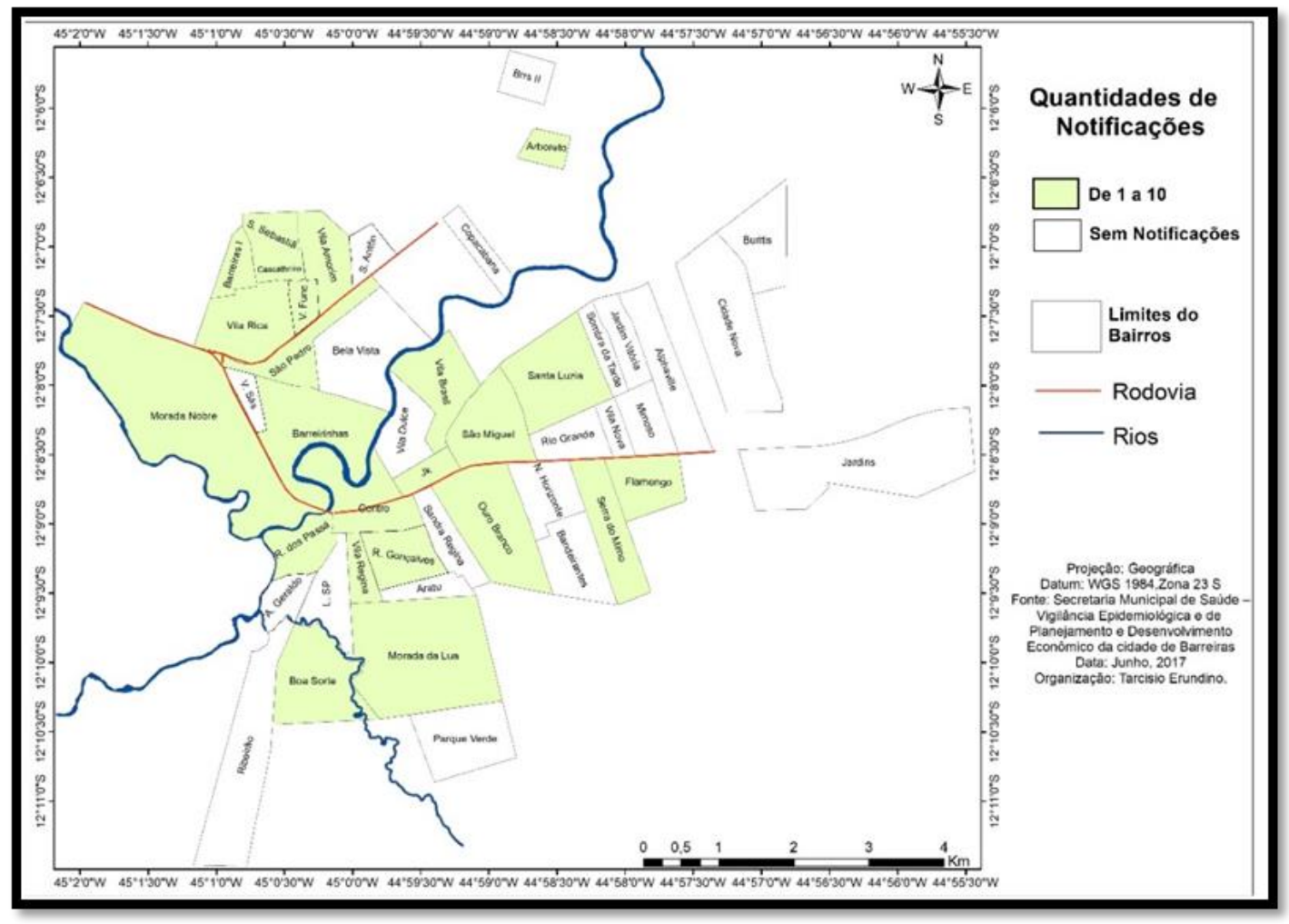

Mapa 05 - Representação dos casos de Zica Vírus nos bairros da cidade de Barreiras-BA referente ao ano de 2016.

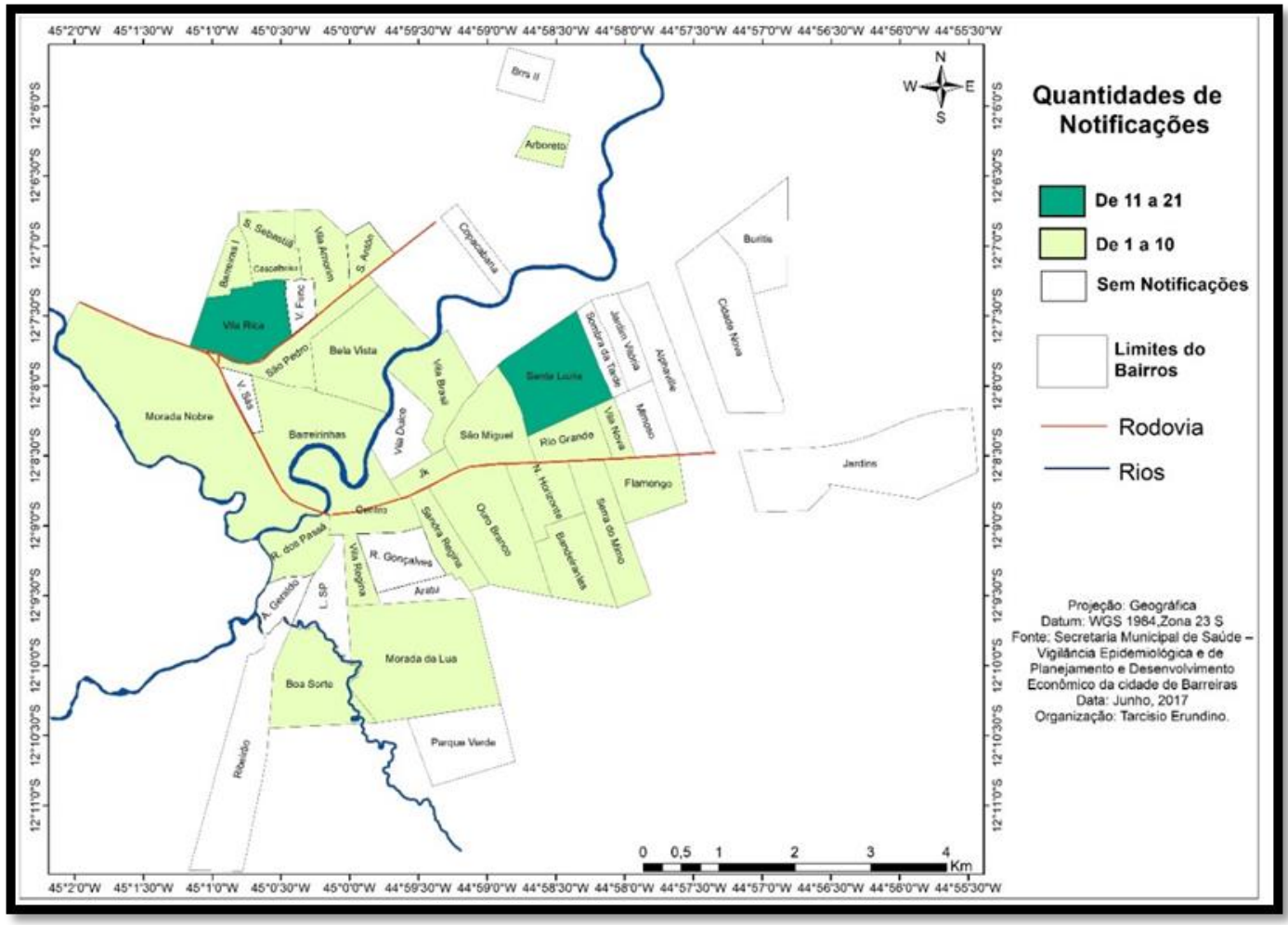




\section{CONSIDERAÇÕES FINAIS}

Esse estudo permitiu a percepção dos bairros que possuem um maior contingente de notificações das arboviroses estudadas, sendo que, os casos de dengue podem ser comparados, já que foram notificados tanto em 2015 quanto em 2016, no entanto, os casos de Zica Vírus e Chicungunya só foram retratados a partir do ano de 2016, por isso não há como ser feita essa comparação também.

Todavia, pode-se perceber que os casos de dengue tiveram de forma geral um decréscimo, isso é evidenciado, inclusive, ao notar que não foi retratado bairros que apresentasse de quarenta e uma a sessenta notificações para o ano de 2016. E houve uma redução nos bairros que apresentaram de onze a quarenta notificações, com os casos em que houveram de uma a dez notificações passando a dominar. No entanto, alguns bairros continuaram apresentando altas notificações dessa arbovirose a exemplo do Vila Rica e Santa Luzia, passando de uma escala entre noventa a cem notificações para oitenta a cem.

Ao ser feita uma análise de campo dos bairros da cidade de Barreiras pôde-se perceber que possivelmente existe uma relação direta entre a alta taxa de casos nesses bairros com o cuidado em relação ao gerenciamento de resíduos, já que, foi visto e registrado por meio de fotografias digitais lixos espalhados de forma inadequada, sendo grandes potenciais para o acumulo de água e proliferação do Aedes aegypti.

A possível vulnerabilidade no gerenciamento de resíduos bem como de infraestrutura se propaga em praticamente todos os bairros da cidade de Barreiras-BA, o que demonstra a necessidade de ser incentivado, de uma forma geral, por meio de políticas públicas a conservação de práticas que favoreçam a erradicação do Aedes Aegypti.

\section{REFERÊNCIAS}

BRASIL, Ministério da Saúde. Como Organizar Um Multirão de Combate ao Aedes aegypti. [Online] Disponível em:<http://portalsaude.saude.gov.br/>. Arquivo capturado em 13 de setembro de 2016.

BCIM- Base Cartográfica Vetorial Contínua do Brasil ao Milionéssimo. Ver. 3. Rio de Janeiro: [2010]. IBGE, Disponível em: <ftp://geoftp.ibge.gov.br/mapeamento_sistematico/base_continua_ao_milionesimo/2_bcim_v 3.zip>. Acesso em: dezembro de 2016. 
BARCELLOS, CHRISTOVAM ET AL. Georreferenciamento de dados de saúde na escala submunicipal: algumas experiências no Brasil. Epidemiol. Serv. Saúde, Brasília, v. 17, n. 1, p. 59-70, mar. 2008.

GUIMARÃES, R. B. Saúde: fundamentos de Geografia humana / Raul Borges Guimarães. São Paulo: Editora Unesp Digital, 2015.

GUADAGNIN, J; Jr, J. S; SANTOS, P.S. Avaliação da vegetação ciliar no município de Barreiras/BA no ano de 2008 utilizando Sensoriamento Remoto e Sistema de Informação Geográfica. In: Simpósio Brasileiro de Sensoriamento Remoto - SBSR, XV. Curitiba, PR. Anais, Brasil, 30 de abril a 05 de maio de 2011, INPE p.6548

\section{IBGE - INSTITUTO BRASILEIRO DE GEOGRAFIA E ESTATÍSTICA. IBGE} Cidades. Disponível em:<http://www.ibge.gov.br/cidadesat> Acesso em: 12 de dez. 2016.

IBGE - InStituto BRASILEIRO DE GEOGRAFIA. Censos Demográficos de 2013. Brasília, 2016b. Disponível em: <http://www.ibge.gov.br>. Acessado em: 12 de dez. 2016.

MINISTÉRIO DA SAÚDE. Monitoramento dos casos de dengue, febre de Chikungunya e febre pelo vírus Zika até a Semana Epidemiológica 48, 2015. Boletim epidemiológico, Brasília: semana 04/01 a 05/12, 2015.

MINISTÉRIO DA SAÚDE. Monitoramento dos casos de dengue, febre de Chikungunya e febre pelo vírus Zika até a Semana Epidemiológica 37, 2016. Boletim epidemiológico, Brasília: semana 3/1/ a 17/09, 2016.

MOREIRA, M. C.; SILVA, D. D. Atlas hidrológico da bacia hidrográfica do rio Grande. 1. ed. Barreiras-BA: Editora Gazeta Santa Cruz, v. 1, 2010.

PIROLI, E.L. Introdução ao geoprocessamento. Ourinhos: Campus Experimental UNESP, 2010. Disponível em: http://cediap.ourinhos.unesp.br/materiais.jsp. 